
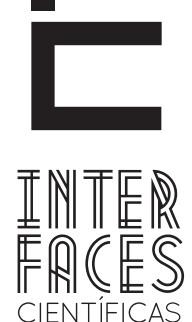

EXATAS E TECNOLÓGICAS

ISSN IMPRESSO - 2359-4934

ISSN ELETRÔNICO - 2359-4942

\title{
BATALHAS DE STANDARDS: \\ FATORES DE INFLUÊNCIA E ESCOLHAS ESTRATÉGICAS
}

Fernando Charles Benigno Neves ${ }^{1}$

\section{RESUMO}

Um Standard é um conjunto de especificações que determinam a compatibilidade de diferentes produtos. A definição de um standard pode determinar o sucesso ou o fracasso de uma empresa nos mercado, assim como seu nível de lucratividade e penetração de mercado. Por isso as batalhas de standards têm sido estudadas para identificar os elementos que influenciam a adoção de um standard e as diversas estratégias conduzidas por empresas. 0 presente artigo

aborda os elementos de influência e apresenta um esquema das estratégias conduzidas pelas empresas, que podem adotar pela adoção de um standard já estabelecido, ou pela criação de novo standard.

\section{PALAVRAS-CHAVE}

Batalhas de Standard. Tecnologias de Rede. Sistemas Industriais. Inovação. 


\section{ABSTRACT}

A standard is a set of specifications that determine the compatibility of different products. The definition of a standard can determine the success or failure of a company in the market, as well as their level of profitability and market penetration. So the battles of standards have been studied to identify the elements that influence the adoption of a standard and the various strategies pursued by companies. This article discusses the influence of elements and presents an outline of the strategies pursued by companies, which can be taken by the adoption of a standard already established, or the new standard of creation.

\section{KEYWORDS}

Battles of Standard. Network Technologies. Industrial Systems. Innovation.

\section{RESUMEN}

Un estándar es un conjunto de especificaciones que determinan la compatibilidad de los diferentes productos. La definición de un estándar puede determinar el éxito o el fracaso de una empresa en el mercado, así como su nivel de rentabilidad y penetración en el mercado. De ahí que las batallas de estándares se han estudiado para identificar los elementos que influyen en la adopción de un standard y las diferentes estrategias adoptadas por las empresas. Este artículo discu- te los elementos de influencia, y presenta un resumen de las estrategias llevadas a cabo por las empresas, que pueden optar por la adopción de un standard ya establecido, o mediante la creación de uno que sea nuevo.

\section{PALABRAS CLAVES}

Batallas de Standard; Tecnologías de Red; Sistemas Industriales; Innovación. 


\section{INTRODUÇ̃̃O}

0 valor de um produto ou serviço cresce à medida que um número maior de consumidores o utiliza. Existem casos em que, para que isto aconteça, um produto deve ser compatível com outros produtos ou tecnologias, de modo que o consumidor obtenha benefícios com sua aquisição. Essa necessidade induz as empresas a adotarem standards, o que incentiva outros usuários para sua utilização, criando um processo que se autoalimenta (FORAY, 1993; CORBEL, 2005). Não raro a viabilidade comercial do produto em si é dependente de tal fator, como o fax, o e-mail, o telefone. Este fenômeno intitula-se "rendimentos crescentes de adoção". A existência de produtos complementares, também, é um fator estimulante dos "rendimentos crescentes de adoção", visto que produtos complementares ${ }^{2}$ aumentam a utilidade da tecnologia e atendem aos desejos de compatibilidade dos usuários (FONTANA, 2008).

A escolha de um determinado standard por um agente no mercado pode trazer inúmeros benefícios para este, principalmente se for fruto de patentes. Pode ser fator decisivo na sobrevivência e controle do mercado (CORBEL; LENTZ; REBOUD, 2008; ARTHUR, 1989). O controle sobre um standard pode dar a uma empresa uma confortável posição no mercado, como no caso da dominância histórica da IBM sobre o mercado de computadores mainframe, da Microsoft no segmento de sistemas e da Intel em microprocessadores (FARRELL e BESEN, 1994).

Por isso inúmeros autores têm se debruçado sobre o assunto, para entender melhor o contexto da concorrência entre empresas para imposição de seus standards. A literatura existente sobre 0 assunto abor$\mathrm{da}$, entre outros elementos, fatores influenciadores $\mathrm{e}$ estratégias adotadas, a partir de exemplos históricos. Decidimos contribuir para o conhecimento do assun-

2. Produtos complementares são aqueles que complementam as funções do produto principal, ou que se integram a ele para criar novas utilizações ao consumidor. É o caso das impressoras e scanners para os computadores; e das lentes intercambiáveis para câmeras fotográficas profissionais. to, ao revisar e sintetizar o conhecimento presente na literatura em torno destes dois pontos, visto que não encontramos nenhum trabalho acadêmico neste sentido. É disso que trata o presente artigo.

Como método de apresentação dos resultados, reunimos os conceitos relacionados, ou similares, em tópicos comuns. Isso nos permitiu eliminar boa parte da redundância em torno de conceitos e ideias, ao mesmo tempo em que aproveitamos da complementariedade de informações dos textos referenciados. Nossa proposição final é: 1) apresentar uma síntese dos fatores determinantes na dominância de um standard no mercado; e 2) apresentar uma síntese das estratégias e táticas usadas pelas empresas para adoção de determinado standard no mercado.

Começamos o artigo por introduzir os principais conceitos sobre standardização, para explanarmos depois sobre batalhas de standards. Em seguida apresentamos os principais fatores que influenciam uma batalha de standards, e concluímos com as estratégias e táticas adotadas pelas empresas.

\section{USO DA STANDARTIZAÇ̃̃O}

Um Standard é um conjunto de especificações que determina a compatibilidade de diferentes produtos (STANGO, 2004), por meio de especificações técnicas que contam com a adesão de um produtor, de forma tácita ou por meio de acordos entre fornecedores de tecnologias (OSHRI e WEEBER, 2006). A standartização apresenta um papel essencial para redução dos custos de produção a partir da redução da variabilidade nos sistemas industriais, ao permitir a intercambialidade de diferentes sistemas e informações (FORAY, 1993; DAVID e SHURMER, 1996). Por isso, historicamente existem diversas batalhas de standards entre as empresas que desenvolvem tecnologias, e que para isso precisam decidir por escolhas estratégicas que as beneficiem (UPDEGROVE, 2006). 
Uma tecnologia standard pode ser uma prática, um produto ou uma técnica (BEURET et al., 2006). Existem dois tipos de standards no mercado: o Standard de Fato e o Standard de Jure (BEURET et al., 2006; STANGO, 2004; OSHRI e WEEBER, 2006). O Standard de Fato é resultado da escolha pelo mercado ou imposição por um concorrente mais forte. O Standard de Jure é resultado uma normatização, oriunda de organizações setoriais ou governamentais (por exemplo, o Instituto Nacional de Metrologia, Normalização e Qualidade Industrial - INMETRO).

Por sua vez, Foray (1993) classifica os standards como de Qualidade e de Compatibilidade. O Standard de Qualidade consiste na construção de um suporte de informação para estabelecer características e padrões mínimos para um produto. Trata-se de referências estabelecidas em comum acordo para reduzir as divergências dentro do mercado e melhor gerir os custos no setor. O Standard de Qualidade, também, contribui para reduzir a incerteza do consumidor sobre a aquisição, visto que este não tem todas as informações possíveis sobre o produto ou serviço.

O Standard de Compatibilidade permite a integração de diferentes sistemas, como telecomunicação, produção de automóveis etc. É o exemplo da definição de formato de tomadas e interruptores no sistema elétrico. Atualmente no Brasil tenta-se estabelecer um standard para carregadores de celulares.

\section{BATALHAS DE STANDARD}

De acordo com Beuret (2006), quando uma empresa desenvolve uma tecnologia de rede, esta escolhe por tornar-se compatível ou incompatível aos seus concorrentes, o que Shapiro e Varian (1999) definem como estratégias de Evolução e Revolução. A Evolução (ou Compatibilidade) é quando sua tecnologia é incompatível com a do concorrente, mas compatível com a geração precedente. Temos o exemplo do DVD e do DIVX discutido por Dranove e Gandal (2003). Revolução (ou Incompatibilidade) é a decisão de utilizar uma tecnologia não compatível com a do concorrente, nem retrocompatível.

Quando a empresa resolve tornar sua tecnologia não compatível, entra em uma batalha por determinar seu standard como o mais aceito pelo mercado. A isso chamamos de "Batalha de Standards". Como exemplo, citamos a concorrência entre George Westinghouse e Thomas Edison para definição do sistema de distribuição de energia elétrica (CORBEL, 2005; SHAPIRO e VARIAN, 1999). O primeiro defendia o sistema de corrente alternada (AC) e o segundo defendia o sistema de corrente contínua (DC). Outro exemplo é o caso da Nintendo e Sony (PlayStation) que utilizam plataformas diferentes no mercado de consoles de jogos eletrônicos. Os jogos vendidos no mercado são utilizáveis somente na plataforma proprietária e cada fabricante tem sua própria patente.

Beuret e outros autores (2006) apresentam os motivos pelos quais uma empresa pode desenvolver uma tecnologia incompatível ou compatível. A decisão por incompatibilidade é muitas vezes menos uma decisão estratégica e mais uma imposição da própria nova tecnologia em desenvolvimento. Quando os primeiros computadores utilizavam fitas cassete para armazenar dados, que foram substituídas pelos disquetes e estes últimos foram substituídos pelos CD's. Neste caso a tecnologia mais antiga apresenta sérias limitações para evolução. Por vezes não é possível lançar produtos com melhores performances indefinidamente, sobre as mesmas bases tecnológicas, e compatíveis com os padrões já existentes.

A partir da revisão da literatura construímos o esquema, representado pela Figura 1, das possibilidades estratégicas que uma empresa pode adotar a partir destas duas abordagens, com suas respectivas implicações. 
Figura 1 - Opções estratégicas

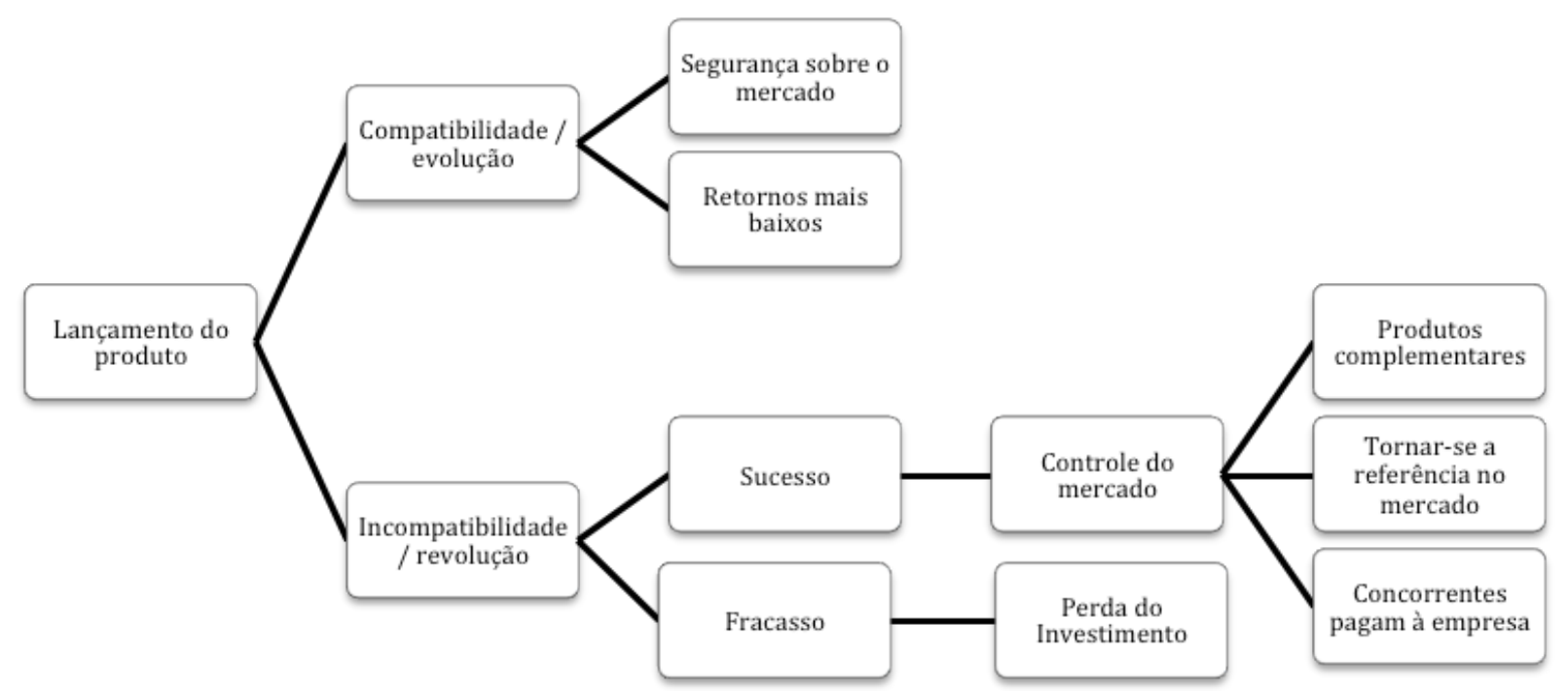

Fonte: 0 autor

A adoção do standard por parte do consumidor não pode ser tomada como certa. Sua decisão de adoção é influenciada, entre outros fatores, por sua avaliação da relação entre os benefícios percebidos e sua capacidade financeira para tomar a decisão de arcar, ou não, com os custos de mudança.

Vejamos o caso da televisão digital. Muito embora já existam muitos canais digitais no mercado, as diferenças em qualidade de imagem, ainda, não foram suficientes para convencer à maior parcela dos consumidores de trocar seus televisores. Ao mesmo tempo, o valor alto dos televisores com recepção digital inibe os consumidores para a aquisição. Isso torna a decisão pela incompatibilidade mais arriscada e exige maiores esforços. Se a empresa fracassa pode perder o investimento realizado. Porém, se bem sucedida, geralmente obtém elevados ganhos, seja por meio das vendas ou por cobrança de royalties sobre patentes, além de futuramente poder tornar-se referência no mercado.
A escolha por compatibilidade é uma decisão menos arriscada. Traz como um dos benefícios a intercambialidade de produtos complementares. Isso torna a percepção do consumidor, na aquisição do produto, mais favorável. É uma estratégia mais segura, porém com retornos mais baixos. Em muitos casos a empresa tem que pagar receitas ao detentor das patentes da tecnologia standard.

\section{FATORES DETERMINANTES NA BATALHA DE STANDARDS}

Na competição pelo estabelecimento de um standard, diversos fatores podem influenciar o resultado final, como é mostrado por Farrell e Besen (1994). Estes fatores foram identificados a partir do estudo de diversos casos de batalhas de standards, analisados historicamente e abordados dentro da literatura revisada. Encontramos nos exemplos históricos de batalhas de standards a influência de um ou mais fatores no resultado da competição. Por isso considera- 
mos fundamental a empresa inseri-los no processo de análise para tomada de decisão e sua compreensão.

É claro que a influência, maior ou menor de determinado fator, está ligada diretamente a um conjunto de condições do mercado. Condições essas que se alteram em virtude do segmento, das empresas competidoras, da natureza do produto, do ambiente legal e do comportamento do consumidor, entre outros elementos. Porém, elas estão presentes, no todo ou em parte.

\section{1 BASE INSTALADA DE USUÁRIOS}

Como afirmam Fontana (2008) e Farrell (1985), a adoção de determinado standard por parte do consumidor é resultado de suas preferências, que recebe influência do desejo de compatibilidade. Desta forma, uma empresa que já possui uma grande quantidade de usuários goza de vantagem para imposição de seu standard (FARRELL e SALONER, 1986). O valor de determinada tecnologia cresce à medida que mais $\mathrm{e}$ mais usuários a utilizam. Ela pode ainda impor restrições à entrada de outros concorrentes por meio da pressão sobre os clientes. Esse controle é importante quando se trata da negociação com grandes clientes, que possuem capacidade de influenciar outros (como o Governo) ou mesmo estabelecer o standard dominante a partir de seu poder de compras.

\subsection{DIREITOS DE PROPRIEDADE INTELECTUAL}

A posse de patentes sobre novas tecnologias é fator decisivo para obter vantagens no mercado. É ao mesmo tempo uma arma na batalha de standards como fonte de receitas. Aqueles que desejarem utilizar a tecnologia devem pagar os direitos, assim como as empresas que produzam produtos complementares. A Qualcomm, por exemplo, detém grande número de patentes sobre tecnologia de telecomunicação móvel, o que resulta em consideráveis rendas sobre licenciamentos para empresas como Broadcom, Nokia e Ericsson (GOODMAN e MYERS, 2005). Porém, os altos ganhos oriundos de patentes podem ser limitados por órgãos reguladores, como deseja o The Federal Trade Comission, nos Estados Unidos (LÉVÊQUE e MÉNIÈRE, 2008).

\subsection{CAPACIDADE DE INOVAÇ̃̃O}

Segundo Shapiro e Varian (1999) a capacidade de uma empresa em rapidamente desenvolver a tecnologia pode criar uma distância da tecnologia concorrente que influencia o mercado. Essa capacidade de inovação tanto pode ser para melhorar a performance da tecnologia como para corrigir eventuais problemas que são comuns na fase inicial de lançamento de produtos. A empresa também pode inovar na ampliação de sua linha de produtos, utilizando da mesma base tecnológica, o que pode ampliar a quantidade de usuários que têm influência na decisão sobre o standard a ser adotado. Recorremos ao recente exemplo da Amazon (com o Kindle) e a Apple (com o iPad) no segmento de leitores de e-Books. Muito embora a Amazon tenha sido pioneira, a Apple conseguiu ampliar as funcionalidades do produto e torná-lo mais atrativo.

\subsection{VANTAGEM DE PIONEIRO}

Ser o primeiro no mercado não garante a liderança, porém o pioneirismo apresenta vantagens estratégicas para as empresas. Seja pelo fato de poder estar à frente no que concerne à P\&D, ou seja pelo fato de poder estabelecer primeiramente contratos com clientes, canais de distribuição e fabricantes de produtos complementares (SHAPIRO e VARIAN, 1999). Não raro o nome da empresa se torna sinônimo de produto, como aconteceu com a Xerox no mercado de fotocopiadoras. Aqueles que chegarem depois ao mercado terão um esforço muito maior para superar as vantagens dos pioneiros.

Manter o primeiro contato com o mercado é poder influenciar os "primeiros adotantes", que têm papel crucial na percepção do mercado sobre a tecnologia que terá sucesso no futuro (FONTANA, 2008). Outro fator relevante é que a aceitação de 
um produto ou serviço no mercado também é resultado da experiência adquirida pelo consumidor. Suas escolhas futuras são reforçadas a partir da experiência adquirida, de modo que muitas vezes nem desconhece outras possibilidades. A esse fenômeno Shapiro e Varian (1999) chamam de "efeito feedback". David (1985) refere-se ao teclado QWERTY como um exemplo típico deste fenômeno.

\subsection{CAPACIDADE DE PRODUÇ̃̃O}

A capacidade de produção, também, é especialmente importante para reduzir custos de produção por meios de ganhos em escala. Essa capacidade é crítica principalmente quando a empresa se encontra em um mercado em rápida expansão, de modo a atender ao mercado e evitar torná-lo atrativo a concorrentes. Clientes mal atendidos podem procurar espontaneamente novos fornecedores.

\subsection{PRODUTOS COMPLEMENTARES}

Empresas que fabricam produtos complementares, ou que de alguma forma utilizam da mesma base tecnológica, podem influenciar o mercado a seu favor (FONTANA, 2008; SHAPIRO e VARIAN, 1999). Consumidores tendem a favorecer empresas que possuam produtos complementares, visto que esses produtos ampliam as funcionalidades dos produtos principais e seu valor de uso. Produtos que utilizam de uma mesma tecnologia, muito embora não sejam complementares, influenciam a percepção do mercado em relação à adoção de um standard. O fato da Sony produzir consoles de jogos foi fator decisivo para o crescimento das vendas de filmes com tecnologia Blu-Ray.

\section{ESTRATÉGIAS E TÁTICAS}

\subsection{PREEMPÇÃO}

A lógica desta estratégia é construir uma posição inicial forte no mercado, de preferência, sendo o pri- meiro fornecedor. Beuret e outros autores (2006) ressaltam que a introdução de um produto no mercado deve ser feita o mais rapidamente possível para surpreender os concorrentes, para poder se beneficiar das retroações positivas. Porém, a empresa deve ter cuidado, porque se lançar muito cedo ao mercado pode ter efeito negativo sobre a qualidade do produto final.

Segundo Shapiro e Varian (1999) esta estratégia é particularmente valiosa se o produto/tecnologia for muito sensível aos ganhos em escala. 0 efeito de realimentação a partir da experiência dos consumidores pode favorecer fortemente a empresa e se transformar em um ciclo que se autoalimenta. Se o custo marginal de produção é nulo, como no caso dos programas de computador, a empresa pode oferecer gratuitamente para consumidores-chave no mercado, ou pagar para que utilizem seu produto.

É o caso de algumas empresas de software que pagam para produtores de microcomputadores para que seus softwares sejam inseridos em computadores novos na modalidade OEM3. O problema desta estratégia é que os consumidores podem não utilizar o produto. Tomemos como exemplo as músicas instaladas em celulares e notebooks novos. Com o tempo as empresas descobriram que os consumidores preferem escolher as suas próprias músicas porque se trata de um gosto muito pessoal.

Outra opção, para quem entra primeiro no mercado, é procurar ampliar ao máximo as possibilidades de uso de seus produtos, assim como os produtos complementares. As receitas oriundas de diversos meios permitem à empresa manipular táticas diferenciadas por aplicações/funcionalidades do produto/tecnologia (BEURET et al., 2006). Ao mesmo tempo é possível estabelecer uma política de preço baixo que os concorrentes não conseguem acompanhar em função de sua estrutura de custos. A Microsoft tem utiliza-

3. Original Equipment Manufacturer (OEM): modalidade diferenciada de distribuição de software na qual são comercializados diretamente pelo fabricante de PC's, sem o uso de embalagens, por um preço diferenciado, ou mesmo sem custos. Os softwares são entregues instalados juntamente com o sistema operacional. 
do esta estratégia há muito tempo, mesmo quando o produto não está completamente estável no nível de desempenho.

\subsection{PROPRIEDADE INTELECTUAL}

A propriedade intelectual, principalmente por meio de patentes, é uma forma de proteger seu mercado e garantir os retornos sobre investimentos realizados, assim como um instrumento de competitividade e inovação. Como dizem Beuret e outros autores (2006), de modo geral, a patente é uma ferramenta de negociação e de controle total. A proteção permitida à empresa por meio da patente garante uma barreira legal à entrada de eventuais novos concorrentes, possibilitando a incorporação da chamada "margem de monopólio” em seus preços (FERREIRA; GUIMARÃES; CONTADOR, 2009).

Entretanto, esta é uma prática muito mais presente em grandes empresas, como atestam os dados apresentados por Ferreira; Guimarães; Contador (2009). Médias e pequenas empresas que não têm capacidade de produção, capacidade financeira, ou competência comercial, têm opção de alianças com empresas mais fortes para desenvolver a tecnologia e explorar o mercado.

A Nicha, empresa detentora de patentes de diodos a laser, ciente do potencial de mercado existente e de sua falta de recursos para explorar este mercado, preferiu estabelecer alianças. Muito embora tenha estabelecido uma agressiva política de gestão de patentes, decidiu aproveitar as vantagens de primeiro entrar num mercado. Precisava também de capacidade de produção para apresentar uma oferta viável à grande escala. Para tal, em dezembro de $2002 \mathrm{fez}$ acordo com a Sony para desenvolvimento de diodos a laser adaptados à produção em grande volume (CORBEL; LENTZ; REBOUD, 2008).

As empresas que desejam controle sobre patentes possuem duas opções. Podem desenvolver sua própria tecnologia ou adquirir de outra empresa. A Procter \& Gamble, detentora de cerca de 35 mil patentes, adota uma estratégia de aquisição por meio de um modelo de «inovação aberta». Atualmente a empresa tem um site no qual potenciais parceiros e ofertantes de tecnologias podem inserir suas propostas.

\subsection{FERRAMENTAS DE COMUNICAÇ̃̃O}

A comunicação é um elemento de extrema importância no jogo empresarial, pois é instrumento de controle e manipulação de percepções dos consumidores e dos concorrentes. Reportamo-nos à batalha entre Westinghouse e Edison para exemplificar a importância da comunicação na batalha de standards. Edison utilizou das ferramentas de comunicação à época para induzir medo nos consumidores em relação à solução concorrente, como podemos ler em Corbel (2005, p. 73):

[...] Edison irá explorar ao máximo outro argumento: 0 perigo. Ele vai utilizar aos poucos todos os canais de comunicação disponíveis à época, capitalizando sobre seu prestígio e sobre as primeiras vítimas por eletrocução nos anos 1888-1889: redação de um panfleto de vinte e quatro páginas intitulado Cuidado! em fevereiro de 1889, artigo dentro do North American Review.

Neste tópico reunimos questões ligadas à comunicação ao mercado na batalha de Standards. Organizamos os fatores principais encontrados na literatura e exemplos encontrados em nossas próprias pesquisas. Consideramos a comunicação, também, como parte do relacionamento com os consumidores, no caso do uso de "grupos pilotos" e táticas similares.

\subsubsection{IMAGEM E REPUTAÇÃO}

Beuret e outros autores (2006) destacam a importância de uso da imagem e reputação da empresa como fator determinante para convencer consumidores de que seu produto é melhor, principalmente se seu produto é incompatível. Essa estratégia é utilizada pela Apple para tentar impor seu leitor multimídia 
iPad. A Amazon, produtora do Kindle e primeira a lançar este tipo de produto no mercado, tenta manter seu produto no mercado com preço mais baixo. Porém, a reputação da Apple em ser uma empresa revolucionária, aliada à capacidade de Steve Jobs em promover suas invenções, tornou o iPad um produto com grande publicidade gratuita.

Por outro lado, se uma empresa possui uma imagem ruim, ou tenha tido histórias de produtos não bem sucedidos no passado, isso pode prejudicar a imposição de seu standard. Assim como a manipulação pouco hábil de standards pode prejudicar a imagem perante o consumidor. A IBM foi pioneira na comercialização de computadores pessoais, porém o problema da incompatibilidade dos componentes com fabricantes genéricos afastou os consumidores da marca. Os consumidores queriam fazer upgrade sem necessariamente comprar componentes da IBM, que eram bem mais caros. Com o tempo usuários de computadores desktop IBM encontravam dificuldades em encontrar peças de reposição que não fossem originais, na contramão das expectativas e tendências do mercado, o que prejudicou suas vendas. Finalmente, em 2005 a IBM vende sua divisão de PC's para a companhia chinesa Lenovo Group.

\subsubsection{GRUPOS PILOTOS E FORMADORES DE OPINIÃO}

Corbel; Lentz; Reboud (2008), assim como Varé e Seifert (2008), destacam a importância de utilizar grupos pilotos e formadores de opinião para influenciar outros consumidores. Como exemplo desta estratégia, citamos a Sony, que ofertou aos primeiros inscritos na Playstation Network preço mais baixo, após o lançamento do disco Blu-Ray de Cassino Royal. Também propôs gratuitamente o download dos traillers dos filmes em HD na PlayStation Store. A Apple, no mercado de players de áudio, utilizou eficientemente dos "formadores de opinião" para chegar à participação de mercado de $76 \%$ deste produto 4 .

4. Fonte: pesquisa de mercado realizada pelo NPD Group www.npd.com.

\subsubsection{USO SELETIVO DA COMUNICAÇÃO}

O conhecimento das expectativas dos clientes ajuda à empresa desenvolver as soluções mais adequadas. Porém, em muitos casos as tecnologias já utilizadas podem estar muito abaixo do desempenho esperado dos consumidores, de modo que estes ficam ávidos por soluções substitutas (BEURET et al., 2006). Os meios publicitários são fortes aliados nesta estratégia, que também implica muitas vezes em capacidade financeira para promover o produto antes de auferir receitas com suas vendas.

Uma empresa pode criar, também, um ambiente de desinformação para gerar grande expectativa e até mesmo bloquear as vendas dos concorrentes. Temos como exemplo o caso do Segway, que é o primeiro veículo elétrico de duas rodas criado para condução humana que se autoequilibra, utilizando o mesmo princípio do corpo humano.

Quando o Segway foi lançado em 2001, inicialmente o inventor criou grande expectativa no público ao anunciar que seu produto revolucionaria o modo de vida das pessoas. O produto nunca cumpriu a promessa, porém a manipulação da expectativa dos consumidores por meio da desinformação criou um ambiente propício para a promoção do mesmo e geração de mídia espontânea.

Uma tática de comunicação, que pode trazer bons resultados, consiste em anunciar bem antes o lançamento de um produto a fim de congelar as vendas dos concorrentes. Corbel; Lentz; Reboud (2008) esclarecem como em 2007 a Sony utilizou do efeito dos anúncios para fazer alarde no mercado sobre a utilização de seu console de jogo PlayStation3 e mobilizar a opinião do mercado a seu favor. Por consequência, em 2008 os estúdios Warner, o maior estúdio do mercado, anunciou sua posição de abandonar o formato HD-DVD. Esse anúncio influenciou outro estúdio, o New Line, o canal HBO e a Digital Playground. 
Shapiro e Varian (1999) destacam que esta tática tem três aspectos que devem ser levados em conta. 0 primeiro aspecto é que as empresas novas devem gozar de confiabilidade do público, para que leve em consideração o anúncio. 0 segundo é que as empresas, que já possuem um portfólio no mercado, podem prejudicar as vendas dos produtos já comercializados por elas, não somente de seus concorrentes. 0 terceiro aspecto é legal. Se a empresa não fizer o lançamento do produto como previsto, pode ser acusada de concorrência desleal. Para isso, ela terá que provar que o atraso no lançamento trata-se de um problema técnico, não de má fé. Microsoft e IBM são outras duas empresas que possuem histórico de utilizar desta tática.

\subsection{COOPERAÇ̃̃O E ALIANÇAS}

Atualmente, poucas tecnologias não são interligadas e dependentes de outras por meio de uma complexa e complementar rede de tecnologias compatíveis e interdependentes. Observemos o fenômeno da convergência digital, no qual várias tecnologias para múltiplos usos estão conectadas para oferecer funcionalidades infinitas aos usuários. Ao mesmo tempo em que uma empresa tenta defender sua tecnologia para auferir lucros com ela, depende de tecnologias que não detém para poder ser útil aos consumidores.

Uma companhia de entregas como FedEx desenvolve um sistema para acompanhamento de entregas aos clientes que precisa ser compatível com os sistemas das operadoras de cartão de crédito e dos bancos, com o sistema de computadores de mão, de operadoras de satélite etc. As redes estão se interconectando e se tornando cada vez mais codependentes.

Por estes motivos, Chen e Hwang (2008) alertam para o fato de que as empresas não devem agir sozinhas em ambientes competitivos. Essa afirmação é resultado de estudo dos autores sobre alianças em ambiente de competição envolvendo standards tecnológicos e de redes. Elas devem estrategicamente estabelecer parcerias e tentar serem ágeis na oferta de uma solução tecnológica. Porém, independente das possibilidades de parceria, Beuret e outros autores (2006) dizem que antes de se lançar dentro de uma batalha de Standards, os combatentes devem considerar a possibilidade de uma solução pacífica.

Num mundo digital, novas batalhas de standard serão cada vez mais operadas em escala complexa, e por meio de cooperações e alianças. A definição de um único standard se torna difícil dentro de um cenário onde centenas de standards são necessários para criar a viabilidade comercial e funcional de um único produto. Em relação a isso Oshri e Weeber (2006, p. 4) alegam que:

É cada vez mais comum para um número de empresas formar o estabelecimento de normas e alianças com o objetivo de desenvolver conjuntamente e patrocinar um determinado standard. Segundo, a maneira pela qual uma norma é decidida também foi alterada [...] o modo de seleção de normas mudou de seleção puramente de mercado ou puramente de negociação de normas para seleção de híbridos, num modo em que a concorrência de mercado e de negociação é vital.

As parcerias foram fator decisivo na batalha entre Sony e Toshiba pela imposição da nova tecnologia a substituir o DVD. Na verdade, como afirmam Corbel e outros autores (2008), não se tratou de uma competição entre duas empresas, mas entre consórcios. A Sun, por exemplo, apoiava a Sony em função da integração da tecnologia Java em oposição ao formato HDI desenvolvido pela Microsoft para o HD-DVD. A aliança que a Sony conseguiu fazer com a Warner, maior produtora de vídeo do mercado, foi crucial para ganhar a batalha com a Toshiba.

Por fim, Varé e Seifert (2008) mostram que o mercado tendenciona para um modelo em que não existem vencedores isolados ou standards definidos unicamente por uma empresa. Esta é a conclusão a partir de seus estudos sobre 76 batalhas de standard que ocorreram a partir do século 19 até 2007. Concluem que num contexto de batalha de standard de era digital os ganhadores são cada vez menos claros, mos- 
trando uma nítida tendência de adoção de standards por meios de negociações de grupos de empresas e gerenciamento de complexos sistemas de licenciamentos e patentes de diversos proprietários.

Desta forma, o modelo de cooperação e competição dentro desta nova realidade aponta para cinco fatores que influenciadores, de acordo com Oshri e Weeber (2006): 1) os atores envolvidos; 2) o valor que eles e outros jogadores adicionar à rede; 3 ) as regras que membros da rede definem para a cooperação (ou concorrência); 4) as táticas que aplicam no cenário de cooperação e competição; e 5) as táticas que aplicam no âmbito das suas cooperativas e regras competitivas do jogo.

\subsection{MERCADO COMPLEMENTAR}

Produtos complementares são aqueles que orbitam em torno de uma tecnologia e que ampliam suas condições de uso e funcionalidades. Impressoras são produtos complementares aos computadores. Sistemas de pagamento com cartão de crédito e débito automático são complementares aos sistemas dos bancos. Bens complementares aumentam o tamanho do mercado e o valor para os clientes.

Segundo Beuret e outros autores (2006, p. 13) “o objetivo de tal mercado é de criar produtos que gerem altos lucros. De maneira geral, ele é eficaz com todas as estratégias, mais particularmente com a estratégia de baixo custo". Algumas empresas podem optar por produzir bens complementares ou apenas licenciar sua tecnologia para outros produtos. Ou ainda apenas permitir a compatibilidade. A decisão de atuar, também, na oferta de bens complementares deve ser tomada de acordo com as variáveis de mercado, de capacidade financeira da empresa e competência de produção destes bens.

Para Corbel; Lentz; Reboud (2008) este foi um fator decisivo no caso da batalha HD-DVD (Toshiba) e Blu-Ray (Sony) para a substituição do formato DVD.
A disponibilidade de filmes no mercado, produzidos por grandes estúdios como Warner, teve impacto significativo para os consumidores. A Sony, que produz o console de jogos PlayStation3, utilizou deste produto para incrementar a venda de seus leitores de vídeo no formato Blu-Ray. A parceria da Sony com grandes estúdios convenceu o mercado que a Sony tinha as melhores alianças e que poderia disponibilizar maior quantidade de vídeos, utilizando seu formato.

\subsection{ABERTURA E CONTROLE}

A estratégia de abertura ou controle do mercado para concorrentes pode ou não ter sucesso, dependendo do potencial do mercado. Até que ponto a abertura terá impacto sobre o tamanho do mercado, de modo a ser vantajoso para a empresa? 0 mercado está limitado pela incapacidade da empresa em suprir a demanda por questões de produção? A empresa sozinha não consegue aumentar a demanda pelos produtos para atingir ganhos em escala? Todos esses fatores carecem de análise cuidadosa por parte dos tomadores de decisão, e são dependentes também da posse de patentes. Como afirmam Beuret e outros autores (2006, p. 14):

[...] em curto prazo ela pode ser útil para estimular o mercado por uma oferta. De fato, se a venda se estagna, então a imagem do produto era limitada pelo preço. [...] No caso no qual as vendas do produto regridem fortemente, mas as do concorrente se estagnam, então um grande potencial se apresenta em preparar cuidadosamente a nova geração.

Muitas vezes, também, a abertura seletiva é necessária para sobrevivência da tecnologia no mercado. Uma empresa faz isso para evitar que outro standard se estabeleça em função de sua política de licenciamento gratuito. Produtores de bens complementares também podem se sentir tentados a realizar parcerias com concorrentes. Desta forma, a abertura é uma maneira de « controlar » o mercado, ou gerenciar perda de fatia do mercado para não ter prejuízos maiores. 


\section{CONCLUSÕES}

Este artigo apresentou a revisão da literatura sobre batalhas de standards, focando sobre dois pontos: fatores determinantes e estratégias/táticas. Iniciamos definindo o que é um standard e o porquê das batalhas de standards. A revisão da literatura nos permitiu concluir que as possibilidades são a compatibilidade e incompatibilidade das tecnologias. A primeira permite maior segurança e menores investimentos. A segunda é uma opção mais arriscada, mas com resultados que podem ser mais lucrativos. Para demonstrar a sequência destas opções construímos um esquema teórico apresentado na Figura 1.

Vários fatores influenciam na determinação de vencedores e perdedores numa batalha de standards, como por exemplo, a capacidade de inovação da empresa. Estes fatores aparecem com maior ou menor influência em diversas exemplos históricos, como por exemplo, a batalha entre Thomas Edison e Westinghouse. Uma empresa, ao compreender a importância destes fatores, pode inseri-los no processo de tomada de decisão para evitar erros.

A partir da análise dos fatores determinantes, apresentamos um conjunto de estratégias e táticas que podem ser adotadas pelas empresas, o que não elimina novas possibilidades não abrangidas neste trabalho e presentes em outros estudos. 0 que representa, também, um limite para este estudo, pois não aborda o total dos estudos sobre o tema. Consideramos a possibilidade de existirem outras estratégias não presentes neste trabalho.

\section{REFERÊNCIAS}

ARTHUR, W. B. Competing Technologies, Increasing Returns, and Lock-In by Historical Events. The Economic Journal, v.99, n.394, 1989, p.116-131.

BEURET, J. R. et al. Processus de standardisation des technologies de réseaux, 2006. Disponível em: <http://students.ti.bfh.ch/beurj1/docs/processusde-standardisation.pdf>. Acesso em: 21 out. 2011.
CHEN, DONG ; HWANG, Y.-S. Network Pattern and Linkage Strength in Standard Competition. Business Renaissance Quaterly, v.3, n.4, 2008.

CORBEL, P. Edison contre Westinghouse: la première bataille moderne pour un standard industriel. Gérer et Comprendre, v.Décembre, n.82, 2005, p.70-77.

CORBEL; LENTZ, F.; REBOUD, S. Les batailles de standards: proposition d'une grille d'analyse et application au cas du remplacement du DVD. Association Internationale de Management Stratégique - AIM. Anais...Nice: 2008.

DAVID, P. A. Clio and the Economics of QWERTY. The American economic review, v.75, n.2, 1985, p.332337.

DAVID, P. A.; SHURMER, M. Formal standards-setting for global telecommunications and information services. Towards an institutional regime transformation? Telecommunications Policy, v.20, n.10, dez. 1996, p.789-815.

DRANOVE, D.; GANDAL, N. The DVD vs. DIVX Standard War: Empirical Evidence of Network Effects and Preannouncement Effects. Forthcoming, Journal of Economics and Management Strategy, p.36, 2003.

FARRELL, J. Standardization, compability, and innovation. Rand Journal of Economics, v.16, n.1, 1985, p.1-14.

FARRELL, J.; BESEN, S. M. Choosing How to Compete: Strategies and Tactics in Standardization. Journal of Economic Perspectives, v.8, n.2, maio 1994, p.117131.

FARRELL, J.; SALONER, G. Installed base and compatibility: Innovation, product preannouncements, and predation. The American economic review, v.76, n.5, 1986, p.940-955. 
FERREIRA, A. A.; GUIMARÃES, E. R.; CONTADOR, J. C. Patente como instrumento competitivo e fonte de informação tecnológica. Gestão da Produção, v.16, n.2, abr.-jun. 2009, p.209-221.

FONTANA, R. Competing technologies and market dominance: standard "battles" in the Local Area Networking industry. Industrial and Corporate Change, v.17, n.6, 21 abr. 2008, p.1205-1238.

FORAY, D. Standardisation et concurrence: des relations ambivalentes. Revue d'économie industrielle, v.63, n.11, 1993, p.84-10.

GOODMAN, D. J.; MYERS, R. A. 3G Cellular Standards and Patents. International Conference on Wireless Networks, Communications and Mobile Computing, v.13, jun. 2005, p.415-420.

LÉVÊQUE, F.; MÉNIÈRE, Y. Technology standards, patents and antitrust, 2007. Disponível em: <http:// ssrn.com/abstract=1133834 . Acesso em: 4 jan. 2011.

OSHRI, I.; WEEBER, C. Cooperation and competition standards - setting activities in the digitization era: The case of wireless information devices. Technology Analysis \& Strategic Management, v.18, n.2, maio 2006, p.265-283.

SHAPIRO, C.; VARIAN, H. R. The art of standards wars. California Management Review, v.41, n.1, 1999, p.32.

STANGO, V. The Economics of Standards Wars. Review of Network Economics, v.3, n.1, 1 jan. 2004, p.1-19.

UPDEGROVE, A. Standards wars: situations, strategies and outcomes. Consortium Stanulards Bulletin, v.V, n.3, 2006, p.10.

VARÉ, A. X.; SEIFERT, R. W. Contextual and tactical changes in standards war: what consequences for "winners"? International Journal of Innovation and Technology Management, v.5, n.4, 2008, p.447-474. 
Recebido em: 8 de Setembro 2014

Avaliado em: 10 de Setembro 2014

Aceito em: 25 de Novembro 2014
1. Formado em administração, especialização em Controladoria, Mestrado em Administração, Doutorando em Ciências da Administração, dentro da linha de pesquisa Sistemas de Informação. Professor de Marketing, Sistemas de Informação, Pesquisa em Administração, Tecnologia da Informação, Organização, Sistemas e Métodos. Professor de cursos de graduação e pós-graduação na área de Administração, Comunicação Social e Secretariado Executivo. Professor membro do Núcleo Docente Estruturante do Curso de Administração e Secretariado Executivo da Universidade da Amazônia Unama. (charlesbenigno@hotmail.com) 